University of Nebraska - Lincoln

DigitalCommons@University of Nebraska - Lincoln

Effects of Noncatastrophic Control Technologies that Alter Life History Parameters on Insect Population Growth: A Simulation Study

James E. Throne

USDA-ARS, Manhattan, KS, james.throne@ars.usda.gov

Throne, James E., "Effects of Noncatastrophic Control Technologies that Alter Life History Parameters on Insect Population Growth: A Simulation Study" (1989). Publications from USDA-ARS / UNL Faculty. 2000. https://digitalcommons.unl.edu/usdaarsfacpub/2000

This Article is brought to you for free and open access by the U.S. Department of Agriculture: Agricultural Research Service, Lincoln, Nebraska at DigitalCommons@University of Nebraska - Lincoln. It has been accepted for inclusion in Publications from USDA-ARS / UNL Faculty by an authorized administrator of DigitalCommons@University of Nebraska - Lincoln. 


\title{
Effects of Noncatastrophic Control Technologies that Alter Life History Parameters on Insect Population Growth: A Simulation Study
}

\author{
JAMES E. THRONE \\ Stored-Product Insects Research and Development Laboratory,
} USDA-ARS, Savannah, Georgia 31403

\begin{abstract}
Environ. Entomol. 18(6): 1050 1055 (1989)
ABSTRACT I investigated the effects of noncatastrophic control technologies that alter life history parameters (such as the use of resistant plant varieties) on the growth of insect populations. I used a computer model to simulate population dynamics of the flat grain beetle, Cryptolestes pusillus (Schönherr). The effects of increasing duration of larval development (by $5,10,15$, or $20 \mathrm{~d}$ ) or decreasing fecundity or larval survival (by 25,50 , or $75 \%$ ) on population growth were simulated. Growth curves for populations with reductions in fecundity or larval survival were nearly identical. The effects of decreasing fecundity or larval survival were apparent during the first generation, whereas the effects of increasing duration of larval development did not become apparent until the second generation. Altering any of the life history parameters resulted in as much as $99 \%$ reduction in population levels at constant temperatures and as much as $87 \%$ reduction in population levels at actual temperatures in a grain bin. The results indicate that use of control technologies that cause even a small change in a life history parameter may have a significant effect on population growth when applied over a growing or storage season. The combination of such technologies with other methods of control may improve the cost effectiveness of pest management techniques, even if the noncatastrophic control techniques do not provide adequate control when used alone.
\end{abstract}

KEY WORDS Insecta, noncatastrophic control methods, simulation model, Cryptolestes pusillus

THE USE OF A CONVENTIONAL INSECTICIDE usually results in the demise of a large proportion of the pest population within a day or two, if an effective pesticide is properly applied. The results of such a catastrophic control method are immediate and obvious. The rate of mortality of the population increases very quickly, but there are usually no long-term effects on the life history parameters of the population. Given a few survivors or some immigrants, the population will continue to grow at the same rate as before the catastrophe.

In contrast, some control measures have longterm effects on insects, rather than killing the insects outright. For example, the use of resistant plant varieties can result in the death of more insects during the immature stage (although these deaths occur over a long period of time, not catastrophically), a longer development period for immatures, and decreased rates of fecundity (e.g., Adetunji 1988). The effects of these noncatastrophic controls on long-term growth of insect populations is not so obvious. For example, it is not readily obvious whether the use of a plant variety that increases the duration of pest larval development by five days will significantly reduce the pest pop-

Names of products are included for the benefit of the reader and do not imply endorsement or preferential treatment by USDA. ulation level over a growing season, as compared with population growth on a susceptible variety.

Simulation techniques provide a useful tool for investigating the effects of changes in life history parameters on long-term population growth. No generalities can be made from simulation studies as to whether a 5-d delay in larval development or a $10 \%$ reduction in fecundity will maintain a population below an economic threshold, because this depends on the insect and crop involved. However, this study investigates the magnitude of the effects that changes in life history parameters, such as those caused by noncatastrophic control technologies, can have on insect population growth and the potential of control technologies that alter life history parameters in pest management programs.

\section{Simulation Model}

Data from the literature describing the life history of the flat grain beetle, Cryptolestes pusillus (Schönherr) (=Laemophloeus minutus Olivier), at $90 \% \mathrm{RH}$ were used to develop a computer model for simulating population dynamics of C. pusillus. I chose this species for the study because there are more quantitative data describing its biology than are available for most other stored-product insects and because the biology and duration of life stages of C. pusillus are typical of many holometabolous 
Table I. Value 01 parameters lor equations used to determine rates 01 biological processes $01 \mathrm{C} . p u . i l l u$. as a lunetion of temperature ("C)

\begin{tabular}{|c|c|c|c|c|c|}
\hline \multirow{2}{*}{ Process } & \multicolumn{3}{|c|}{ Parameters } & \multirow{2}{*}{$\mathrm{n}$} & \multirow{2}{*}{ RZ } \\
\hline & $a$ & $b$ & $\mathrm{c}$ & & \\
\hline \multicolumn{6}{|c|}{ Development rate (I/days) } \\
\hline Egg & 0.022306 & -0.003786 & 0.000352 & 4 & 0.91 \\
\hline Larva & -0.044196 & 0.002606 & $0 . \quad$ oo42 & 4 & 0.97 \\
\hline Prepupa & -0.277397 & 0.019536 & 0 & 3 & 0.96 \\
\hline Pupa & -0.137752 & 0.011135 & 0 & 3 & 0.94 \\
\hline \multicolumn{6}{|l|}{ Mortality (\%) } \\
\hline Egg & 28.639299 & -2.058570 & 0.038621 & 4 & 0.64 \\
\hline Larva & 430.457700 & -31.042115 & 0.576030 & 4 & 0.99 \\
\hline Prepupa & 116.871997 & -7.049552 & 0.105508 & 4 & 0.99 \\
\hline Pupa & -78.113984 & 7.205949 & -0.153258 & 4 & 0.99 \\
\hline \multicolumn{6}{|c|}{ Longevity (I/days) } \\
\hline Male & -0.000831 & 0.000212 & 0 & 5 & 0.92 \\
\hline Female & 0.009734 & -0.000416 & $0 . \quad$ oo12 & 5 & 0.91 \\
\hline \multicolumn{6}{|c|}{ Fecundity (eggs/female/lifetime) } \\
\hline & 11.296613 & -8.657113 & 0.662728 & 5 & 0.99 \\
\hline
\end{tabular}

All equations are of the form: $\mathrm{Y}=a+\mathrm{bX}+\mathrm{cXz}$, where $\mathrm{X}=$ temperature $\quad$ ("C).

insect species. Although this model has not been validated, unvalidated models and models of hypothetical insect species have proven useful for investigating control strategies (e.g., Sinclair \& Alder 1985, Longstaff 1988). Output from the model in this study was similar to C. pusillus population growth in small outdoor bins (F. H. Arthur \& J.E.T., unpublished data). The intent of this paper is not to make recommendations for control of C. pusitlus, but rather to investigate effects of changes in life history parameters on subsequent growth of insect populations.

Cryptolestes pusillus typically infest grain stored at high temperature and high moisture content. At $32.2^{\circ} \mathrm{C}$ and $90 \% \mathrm{RH}$, development from oviposition to adult emergence takes $27.3 \mathrm{~d}$ on wheat (Bishop 1959). Eggs usually are laid in cracks in the grain and hatch in $3.5 \mathrm{~d}$. Larvae feed on the grain, and the larval stage lasts $17.9 \mathrm{~d}$, The non-feeding prepupal stage lasts $3.2 \mathrm{~d}$ at $30^{\circ} \mathrm{e}$ and $90 \% \mathrm{RH}$ (Davies 1949). The pupal stage lasts $4.4 \mathrm{~d}$ at $32,2^{\circ} \mathrm{e}$ and $90 \%$ RH (Bishop 1959), Males and females feed on grain. Males live $98 \mathrm{~d}$ at $32.5^{\circ} \mathrm{e}$ and $90 \% \mathrm{RH}$ (Bishop 1959). Sixty-three percent of females start laying eggs within $4 \mathrm{~d}$ after emerging at $25^{\circ} \mathrm{e}$ and $75 \%$ RH (Davies 1949), Females live $138 \mathrm{~d}$ at $32.5^{\circ} \mathrm{C}$ and 90\% RH (Bishop 1959) and lay 226.8 eggs during the first $12 \mathrm{wk}$ of adult life at $30^{\circ} \mathrm{e}$ and $90 \%$ RH (Currie 1967),

The first step taken in developing the model was to describe the relationship between temperature and the rate of development of the immature stages. These relationships were described by either linear or quadratic equations, depending on which method resulted in a higher $R 2$, Parameters for these equations are listed in Table 1. More sophisticated nonlinear techniques (e.g., Wagner et al. 1984) were not used because the available data were usually within the linear portion of the development rate curve and because there were only three to five means to which the curves were fit. Subsequent simulations were always within the range of temperatures of the original data. Temperature limits for development were 17 and $30^{\circ} \mathrm{e}$, because of lack of data outside this range,

Variation in development rate was simulated with a time-varying distributed delay (Manetsch 1976). The basis for this method is that there is a mean, p., and a variance, $\sim$, associated with the time required to complete development of a stage at a given temperature. The shape of the curve describing the number of individuals leaving a stage over time can be approximated by a member of the Erlang family of density functions. The specific function is designated in the model by the parameter $\mathrm{K}$, which is calculated as $p .2 / U^{2}$. There were no measures of variation in rate of development reported in the literature, so a standard deviation (s) was estimated for each mean duration of development $(x)$ using the equation of Shaffer (1983), where:

$$
s=0,209 \times 0^{73} .
$$

A K for each stage was determined by first calculating a $\mathrm{K}$ for each temperature for which data were available, and then taking the average of K's at the different temperatures. $\mathrm{K}$ should be less than p./(2 x DT), where DT is the time step in the model, to ensure stability (Abkin \& Wolf 1976), The time step in this model is $0.1 \mathrm{~d}$. Therefore, $\mathrm{K}$ for each stage was not allowed to exceed ,. .5.

Quadratic equations were used to describe the relationships between temperature and mortality for the immature stages (Table 1). Adults were distributed at a 1:1 sex ratio (Williams 1954). Longevity was described by a linear equation for males and a quadratic equation for females (Table 1), Because of the lack of data, the preoviposition pe- 
riod was assumed to last four days at all temperatures (Davies 1949). Fecundity data from Currie (1967) were modified for use in the model. Currie (1967) reported the number of eggs laid during the first $12 \mathrm{wk}$ of adult life. The number of eggs laid during $12 \mathrm{wk}$ was multiplied by female longevity divided by 12 to obtain an estimate of total eggs laid during the life of a female. These estimates agree with the limited data reported on fecundity over a lifetime (Davies 1949). A quadratic equation was fit to the data (Table 1). The number of eggs laid was divided evenly over the female's lifetime at a constant temperature.

\section{Simulations}

Delays in Development. Simulations were run to determine whether the stage at which the developmental delay is applied affects population growth. Simulations were started with one mature male and one mature female and run at constant temperatures of 17 and $30^{\circ} \mathrm{C}$. A developmental delay of $5 \mathrm{~d}$ was applied to the egg, larval, prepupal, or pupal stage. At $17^{\circ} \mathrm{C}$, the number of adults present at monthly intervals for one year was identical no matter which stage experienced delayed development. At $30^{\circ} \mathrm{C}$, the number of adults present at biweekly intervals for 6 mo was within $2.5 \%$ of the values when the delay was applied during the larval stage. Therefore, in subsequent simulations the developmental delay was always applied to the larval stage. The larval stage would most likely be the stage affected in actual conditions, because this is the only immature stage which feeds.

Next, the effect of varying the length of the delay on subsequent population growth was investigated. Developmental delays of $0,5,10,15$, or $20 \mathrm{~d}$ were applied to the larval stage. These simulations, and all subsequent simulations, were started with one mature female and one mature male. Temperature regimes in these simulations, and all subsequent simulations, were constant $20^{\circ}, 25^{\circ}$, and $30^{\circ} \mathrm{C}$, and actual temperatures measured in a grain bin.

Actual temperatures were recorded in a cylindrical metal bin, near Bamberg, Bamberg Co., S.C., containing about 3,000 bushels of corn (R. T. Arbogast \& J.E.T., unpublished data), a favorable host of C. pusillus. Temperature was monitored at a point about $0.2 \mathrm{~m}$ from the wall at the south compass point and about $0.4 \mathrm{~m}$ deep. The temperature was scanned at 5 -min intervals and a mean was recorded hourly with an Omnidata Easylogger (Omnidata International, Logan, Utah). Input to the model was one daily temperature, which was the mean of the 24 hourly mean temperatures, because there was little diurnal variation in grain temperature. Monitoring was begun on 14 October 1986, shortly after the grain was placed in storage and ended in August 1987, when the grain was removed from storage. Simulations were run onlv until the end of June 1987, after which the temperature of the grain began to exceed $31^{\circ} \mathrm{C}$. Again, the upper temperature limit in the model was $30^{\circ} \mathrm{C}$. Therefore, any temperatures during the month of June that exceeded $30.0^{\circ} \mathrm{C}$ were rounded down to $30.0^{\circ} \mathrm{C}$. Temperatures during the month of June never reached $31^{\circ} \mathrm{C}$. Winter and spring temperatures fell below the minimum temperature for development in the model $\left(17^{\circ} \mathrm{C}\right)$ from 3 December 1986 through 26 April 1987. In the simulations, no development occurred during this period. This is probably not unrealistic because most stored-product insects develop very slowly below $20^{\circ} \mathrm{C}$ (Howe 1965).

Decreased Larval Survival. I investigated the effects on subsequent population growth of decreasing larval survival by 25,50 , or $75 \%$ of reported values. Simulation conditions were as for the developmental delay simulations. Without any decrease, larval survival (at $90 \% \mathrm{RH}$ ) was $31.7 \%$ at $17^{\circ} \mathrm{C}, 65.3 \%$ at $21^{\circ} \mathrm{C}, 87.9 \%$ at $25^{\circ} \mathrm{C}$, and $82.2 \%$ at $30^{\circ} \mathrm{C}$ (Davies 1949).

Decreased Fecundity. The effects of decreasing fecundity by 25,50 , or $75 \%$ on subsequent population growth also were investigated. Again, simulation conditions were the same as developmental delay simulations. Without any decrease, fecundity was 62.3 eggs/female during her lifetime at $17.5^{\circ} \mathrm{C}$, 153.1 at $22.5^{\circ} \mathrm{C}, 210.4$ at $25^{\circ} \mathrm{C}, 270.8$ at $27.5^{\circ} \mathrm{C}$, and 349.7 at $30^{\circ} \mathrm{C}$ (adapted from Currie 1967).

\section{Results}

Developmental Delays. After $180 \mathrm{~d}$ at 20, 25, or $30^{\circ} \mathrm{C}$, there were $55 ; 9,531$; or $2,833,071$ adult C. pusillus present when no larval delay was incurred (Fig. 1). At bin temperatures, there were 697 adult C. pusillus present at the end of the storage period (30 June) when no larval delay was incurred. At constant temperatures, reduction in number of adults present after $180 \mathrm{~d}$ was greater as length of the delay and temperature increased (Table 2). As much as a $99.1 \%$ reduction in the number of adults present after $180 \mathrm{~d}$ was achieved, as compared with populations that did not have delays in larval development.

Growth curves for populations with developmental delays of $0,5,10,15$, or $20 \mathrm{~d}$ began to diverge at about $140 \mathrm{~d}$ at $20^{\circ} \mathrm{C}$, at about $80 \mathrm{~d}$ at $25^{\circ} \mathrm{C}$, and at about $55 \mathrm{~d}$ at $30^{\circ} \mathrm{C}$ (Fig. 1). (Parallel lines in Fig. 1 actually indicate diverging growth curves because the number of adult insects is plotted on a logarithmic scale.) Based on data used to develop the model, this is about twice the duration of immature development at each temperature. (Duration of immature development is $62 \mathrm{~d}$ at $20^{\circ} \mathrm{C}$, $41 \mathrm{~d}$ at $25^{\circ} \mathrm{C}$, and $27 \mathrm{~d}$ at $30^{\circ} \mathrm{C}$.) Therefore, the effects of developmental delays started to become apparent shortly after second-generation adults began to emerge.

Percentage of reduction in the number of adults in populations with developmental delays in creased steadily beginning about day 150 at $20^{\circ} \mathrm{C}$ was fairly constant after about day 100 at $25^{\circ} \mathrm{C}$, 


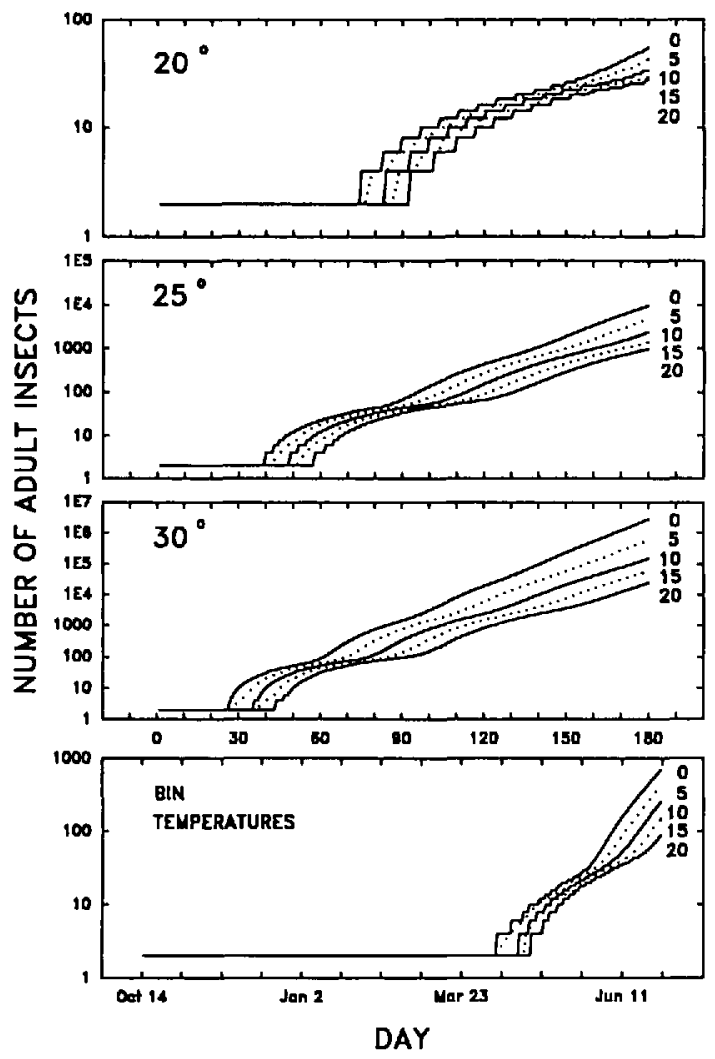

Fig. 1. Growth curves for C. pusillus populations experiencing $0-, 5-, 10-, 15-$, or $20-\mathrm{d}$ delays in larval development. Note the logarithmic scale on the $\mathrm{Y}$ axis. $1 \mathrm{EX}=10^{x}$.

and after about day 70 at $30^{\circ} \mathrm{C}$ (Fig. 2). This is shortly after second-generation adults begin to emerge. At bin temperatures, the percentage of reduction in number of adults present in popula-

Table 2. Percentage reduction in number of $C$. pusillus adults after $180 \mathrm{~d}$ at constant temperatures and on 30 June $(259$ d) at bin temperatures in populations experiencing changes in life history parameters

\begin{tabular}{|c|c|c|c|c|}
\hline & $20^{\circ}$ & $25^{\circ}$ & $30^{\circ}$ & $\begin{array}{c}\text { Bin } \\
\text { temp. }\end{array}$ \\
\hline \multicolumn{5}{|c|}{ Developmental delays } \\
\hline \multicolumn{5}{|c|}{ Delay, days } \\
\hline 5 & 21.8 & 50.5 & 79.5 & 39.9 \\
\hline 10 & 40.0 & 75.3 & 94.7 & 63.3 \\
\hline 15 & 47.3 & 85.4 & 98.0 & 78.5 \\
\hline 20 & 50.9 & 89.7 & 99.1 & 87.2 \\
\hline \multicolumn{5}{|c|}{ Decreased larval survival } \\
\hline \multicolumn{5}{|c|}{ \% Reduction in survival } \\
\hline 25 & 32.7 & 53.4 & 68.8 & 41.5 \\
\hline 50 & 58.2 & 83.4 & 93.6 & 71.6 \\
\hline 75 & 80.0 & 96.7 & 99.5 & 91.0 \\
\hline \multicolumn{5}{|c|}{ Decreased fecundity } \\
\hline \multicolumn{5}{|c|}{ So Reduction in fecundity } \\
\hline 25 & 32.7 & 53.9 & 69.2 & 41.9 \\
\hline 50 & 58.2 & 83.8 & 93.6 & 72.2 \\
\hline 75 & 80.0 & 96.9 & 99.5 & 91.2 \\
\hline
\end{tabular}

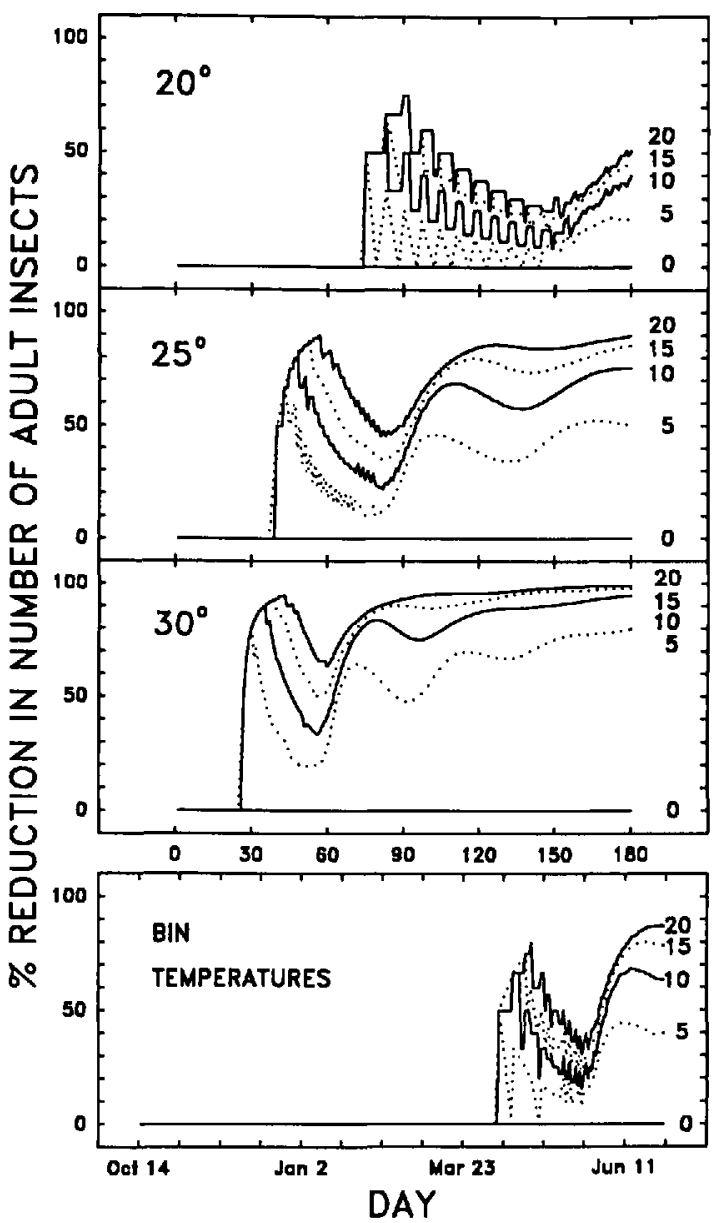

Fig. 2. Percentage of reduction in number of $C$. pusillus adults in populations experiencing $0-, 5-, 10-$ 15-, or 20-d delays in larval development.

tions with developmental delays began to increase in mid-May and leveled off about mid-June (Fig. 2).

Decreased Larval Survival. At constant temperatures, there was a greater reduction in number of adults present after $180 \mathrm{~d}$ as reduction in larval survival and temperature increased (Table 2). As much as a $99.5 \%$ reduction in the number of adults after $180 \mathrm{~d}$ was achieved, as compared with populations that did not have reductions in larval survival.

Growth curves for populations with $0,25,50$, or $75 \%$ reductions in larval survival began to diverge after about $75 \mathrm{~d}$ at $20^{\circ} \mathrm{C}$, after $40 \mathrm{~d}$ at $25^{\circ} \mathrm{C}$, and after $30 \mathrm{~d}$ at $30^{\circ} \mathrm{C}$ (Fig. 3), or when first generation adults began to emerge. Percentage reduction in the number of adults in populations experiencing developmental delays also began to increase steadily at about the time first-generation adults began to emerge (Fig. 4). At bin temperatures, the percentage of reduction in the number of adults in 


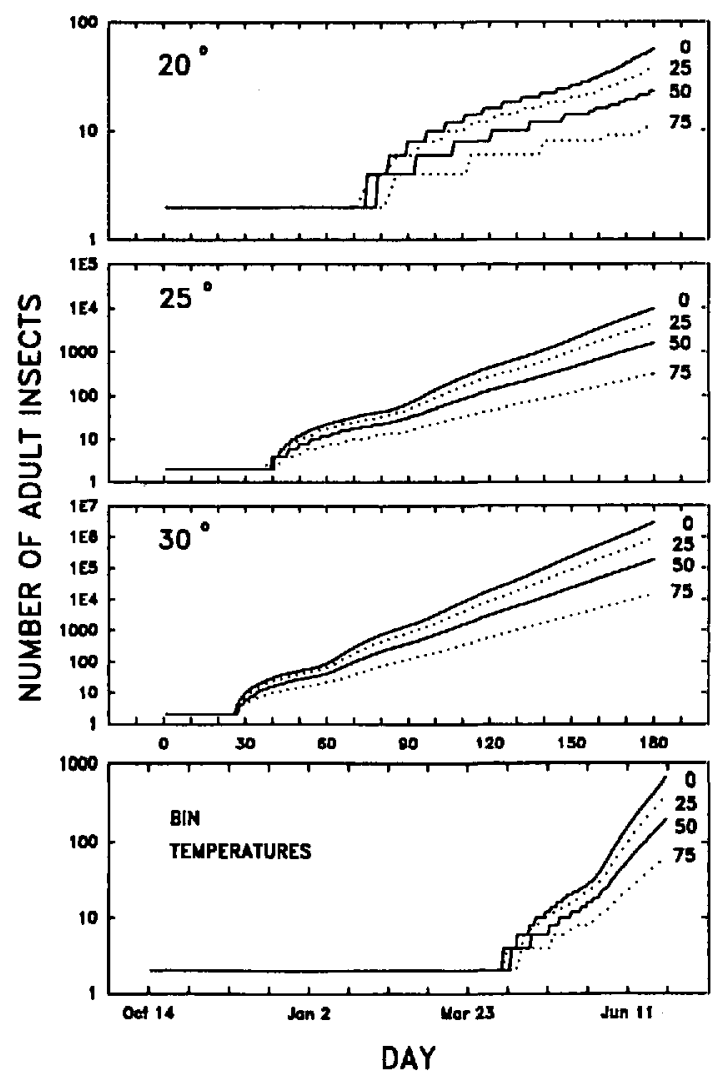

Fig 3. Growth curves for C. pusillus populations experiencing $0,25,50$, or $75 \%$ decreases in larval survival. Note the logarithmic scale on the $\mathrm{Y}$ axis. $1 \mathrm{EX}=$ $10^{x}$.

populations with reductions in larval survival increased steadily beginning about mid-April (Fig. 4).

Decreased Fecundity. Growth curves for populations with decreased fecundity were nearly identical to those for populations with decreased survival. Therefore, no figures are shown for these results. Percentage reduction in number of adults present at the end of $180 \mathrm{~d}$ at constant temperatures or at the end of the storage period at bin temperatures is shown in Table 2 .

\section{Discussion}

Numerous studies have shown that use of noncatastrophic control technologies can adversely affect life history parameters of insect populations (e.g., Adetunji 1988). Differences in variety were responsible for as much as an 8 -d delay in the duration of development of rice weevils, Sitophilus oryzae (L.) (Coleoptera: Curculionidae), feeding on sorghum (Adetunji 1988). In my study, a 10-d delay in larval development reduced the population level at the end of the storage period (at actual fluctuating temperatures) by $63 \%$ as compared with populations that had no delay in development. Even a 5 -d delay reduced the population level by $40 \%$. Clearly, even a small delay in development may

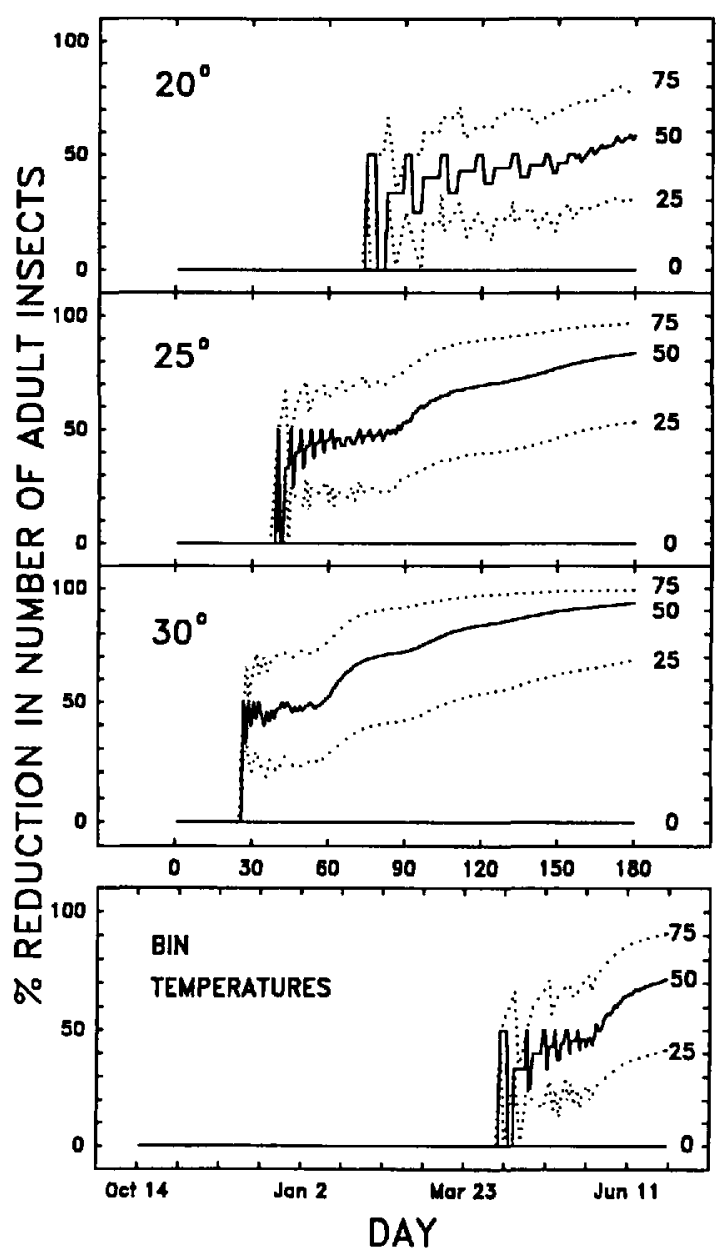

Fig. 4. Percentage of reduction in number of $C$. pusillus adults in populations experiencing $0,25,50$, or $75 \%$ decreases in larval survival.

have a significant effect on the population level when applied over a growing or storage season.

Rice weevil fecundity can be reduced by as much as $96 \%$ depending on sorghum variety (Adetunji 1988). Although such high levels of reduction in fecundity were not tested in this study, even a $25 \%$ decrease in fecundity resulted in a $42 \%$ reduction in population level during the storage period. Anywhere from a 33 to $62 \%$ decrease in immature survival occurs when rice weevils are fed on different sorghum varieties (Adetunji 1988). Again, in my study, even a $25 \%$ reduction in larval survival resulted in $41 \%$ reduction in population level at the end of the storage period.

These results indicate that control technologies that cause even a small change in a life history parameter have potential for use in a pest management program. In a situation where a pest population regularly exists near the economic threshold level or only reaches the economic threshold level at the end of the season, a 5 or $10 \%$ decrease in population level throughout the season may negate 
the need for remedial pesticide applications or may reduce the number of applications required.

For example, in the simulation using fluctuating bin temperatures presented in this study, a $75 \%$ reduction in fecundity or larval survival delayed population growth by 1 mo compared with the population that had no reduction in fecundity or survival. If a grower who stored corn yearround to feed hogs normally fumigated his grain in June and August to kill insects, then a 1-mo delay in insect population growth may allow that grower to fumigate only once during the storage season.

A small change in duration of development coupled with small changes in rate of fecundity and survival could result in great decreases in population level. Adetunji (1988) found that varieties of sorghum on which increases in duration of development occurred were the same varieties on which immature mortality was increased. Fecundity was also lower on varieties on which duration of development was lengthened and immature mortality was increased.

In conclusion, noncatastrophic control technologies that adversely affect life history parameters of insect populations may provide long-term control of pest populations even if the changes in the life history parameters are small. The combination of such control technologies with other methods of control may improve the cost effectiveness of pest management techniques, even if the noncatastrophic control techniques do not provide adequate control when used alone. When possible, researchers should use simulation techniques to determine whether the effects of observed changes in life history parameters will be of sufficient magnitude to provide partial or complete control in the particular control situation being studied.

\section{Acknowledgment}

I thank J. E. Baker for suggesting this study; and F. H. Arthur, J. E. Baker, L. D. Cline, C. J. Eckenrode, D. W. Hagstrum, and L. Li for helpful comments on earlier versions of the manuscript.

\section{References Cited}

Abkin, M. H. \& C. Wolf. 1976. Distributed delay routines: DEL, DELS, DELF, DELLF, DELVF,
DELLVF. Michigan State University, Department of Agricultural Economics Computer Library for Agricultural Systems Simulation Document 8.

Adetunji, J. F. 1988. A study of the resistance of some sorghum seed cultivars to Sitophilus oryzae (L.) (Coleoptera: Curculionidae). J. Stored Prod. Res. 24: 6771 .

Bishop, G. W. 1959. The comparative bionomics of American Cryptolestes (Coleoptera-Cucujidae) that infest stored grain. Ann. Entomol. Soc. Am. 52: 657665.

Currie, J. E. 1967. Some effects of temperature and humidity on the rates of development, mortality and oviposition of Cryptolestes pusillus (Schönherr) (Coleoptera, Cucujidae). J. Stored Prod. Res. 3: 97-108.

Davies, R. G. 1949. The biology of Laemophloeus minutus Oliv. (Col. Cucujidae). Bull. Entomol. Res. 40: $63-82$.

Howe, R. W. 1965. A summary of estimates of optimal and minimal conditions for population increase of some stored products insects. J. Stored Prod. Res. 1: $177-184$.

Longstaff, B. C. 1988. Temperature manipulation and the management of insecticide resistance in stored grain pests: a simulation study for the rice weevil, Sitophilus oryzae. Ecol. Model, 43: 303-313.

Manetsch, T. J. 1976. Time-varying distributed delays and their use in aggregative models of large systems. IEEE Trans. Syst. Man Cybern. SMC-6: 547553.

Shaffer, P. L. 1983. Prediction of variation in development period of insects and mites reared at constant temperatures. Environ. Entomol. 12: 1012-1019.

Sinclair, E. R. \& J. Alder. 1985. Development of a computer simulation model of stored product insect populations on grain farms. Agric. Syst. 18: 95-113.

Wagner, T. L., H. I. Wu, P. J. H. Sharpe, R. M. Schoolfield \& R. N. Coulson. 1984. Modeling insect development rates: a literature review and application of a biophysical model. Ann. Entomol. Soc. Am. 77: $208-225$.

Williams, G. C. 1954. Observations on the life history of Laemophloeus minutus (OI.) (Col. Cucujidae) when bred on various stored cereals and cereal products. Bull. Entomol. Res. 45: 341-349.

Received for publication 11 Oclober 1988; accepted 15 March 1989. 